\title{
The influence of technology elements on the production of bioethanol from sugar sorghum
}

\author{
Oksana Muliarchuk ${ }^{1}$, Olena Koberniuk ${ }^{1}$, Tetiana Bilyk ${ }^{1}$, Petro Bezvikonnyi ${ }^{1}$, and Valeriy \\ Tarasyuk $^{1}$ \\ ${ }^{1}$ State Agrarian and Engineering University in Podilia, 32300 Kamianets-Podilskyi, Ukraine
}

\begin{abstract}
The search for promising raw materials for the production of bioethanol is an urgent task of the present. An effective sugar crop for bioethanol production is sugar sorghum, which per hectare of crops provides 90-100 $t /$ ha of biomass with sugar content of $18-20 \%$. The article presents the results of the influence of mineral nutrition on the productivity and yield of bioethanol from sugar sorghum plants in the zone of the Western Forest-steppe of Ukraine. Investigation of the elements of the technology of cultivating sugar sorghum for the production of biofuels was conducted with the Sugar 1 variety and the Hybrid Honey F1 in three grades of nutrient backgrounds - no fertilizers, $\mathrm{N}_{90} \mathrm{P}_{90} \mathrm{~K}_{90}$ and $\mathrm{N}_{120} \mathrm{P}_{120} \mathrm{~K}_{120}$ using herbicide 2,4-D. For the introduction of sorghum herbicide 2,4-D in the steps of 1.51 / ha in the phase of 3-4 leaves, there was a good increase in plant height and diameter of the stems. The increase in the yield of green mass of sorghum compared to non-fertilized control at the rate of $\mathrm{N}_{90} \mathrm{P}_{90} \mathrm{~K}_{90}$ introduction into the Sugar 1 variety was 6.1 tons / ha, and the Hybrid Honey F1 was 6.5 tons / ha; for the norm $\mathrm{N}_{120} \mathrm{P}_{120} \mathrm{~K}_{120}$ respectively 7.9 and $8.6 \mathrm{t} /$ ha. The yield of bioethanol by sorts of sorghum on the background of the introduction of $\mathrm{N}_{90} \mathrm{P}_{90} \mathrm{~K}_{90}$ was respectively 2.18 and $2.27 \mathrm{t} /$ ha, solid fuels - respectively 11.9 and $12.4 \mathrm{t} /$ ha, bioenergy respectively 243 and $254 \mathrm{GJ}$; on the background of the introduction of $\mathrm{N}_{120} \mathrm{P}_{120} \mathrm{~K}_{120}$ and the application of 2,4-D herbicide, the bioethanol yield was 2.25 and $2.32 \mathrm{t} /$ ha respectively, solid fuels - respectively 12.3 and $12.6 \mathrm{t} / \mathrm{ha}$, bioenergy - respectively 252 and $259 \mathrm{GJ}$.
\end{abstract}

\section{Introduction}

The increase in industrial production and global processes in the modern world lead to increased energy use and environmental degradation. The development of non-traditional and renewable energy sources is an important factor in increasing the level of energy security, reducing the use of fossil fuel resources (including imported), industrial and agricultural development, and reducing the negative impact of energy on the environment and improving the quality of life of citizens [1].

Taking into account the agrarian orientation of the Ukrainian economy, renewable energy sources are the most rapidly developing bioenergy. Perspective in this regard is the use of energy of photosynthetic activity of plants in the form of bioethanol, the volume of production of which over the past decade increased more than three times. It is used 
predominantly in the form of fuel mixtures to increase the octane number: the addition of $10 \%$ bioethanol to gasoline can reduce the emission of aerosol particles by $50 \%$, and carbon dioxide emissions by $30 \%[2,3,4]$.

Within the framework of the baseline scenario of the Energy Strategy, envisaged the transition to the use of petrol with $10 \%$ ethanol content by 2020 and $15 \%$ ethanol content by 2030 and the transition to the use of diesel fuel with $7 \%$ biodiesel content by 2030 is. In general, the European Commission plans to replace up to $20 \%$ of conventional fuels by 2020 in the transport sector [5].

The search for promising raw materials for the production of bioethanol is an urgent task of the present. An effective sugar crop for bioethanol production is sugar sorghum, which per hectare of crops provides $90-100 \mathrm{t} /$ ha of biomass with sugar content of $18-20 \%$ juice $[6,7]$. The yield of juice is up to $60 \%$ of the green mass. After removing juice, the sorghum moisture content does not exceed $40 \%$, so they can be raw material for the production of solid biofuels (fuel pellets or briquettes) $[8,9]$. Efforts of many scientists are aimed at increasing the yield of sorghum in the framework of a multinational project aimed at improving the quality of raw materials as a sustainable source of biofuel production.

Sorghum sugar is not a cumbersome culture. It grows well on both light and heavy granulometric soil compositions. The optimum soil density is $1.1-1.2 \mathrm{~g} / \mathrm{cm}^{3}$, the soil solution reaction is $\mathrm{pH}$ 6.0-7.5. The minimal temperature of seed germination is $+10-15$ ${ }^{\circ} \mathrm{C}$, optimum $-+25-30{ }^{\circ} \mathrm{C}$; minimum temperature of staining $-+15-18{ }^{\circ} \mathrm{C}$; temperature causing damage to stairs $-+5^{\circ} \mathrm{C}$. The optimum temperature of growth and development of plants is $+25-30{ }^{\circ} \mathrm{C}$. The sum of active temperatures is higher than $+5{ }^{\circ} \mathrm{C}$ during the growing season within the limits of $2250-2500{ }^{\circ} \mathrm{C}$. Minimum reserves of moisture in an arable layer of soil for obtaining friendly stairs within $20-30 \mathrm{~mm}$. Culture is capable of well tolerating soil and air drought; its critical period for soil moisture is due to the time of ejection of panicles - maturation [10].

By the relation to light, this is a short-day culture. The optimum area of the leaf surface varies within 40-75 thousand $\mathrm{m}^{2} /$ ha. Duration of the growing season depends on the variety or hybrid within 90-130 days. The technology of growing high and stable yields of sugar sorghum is based on the rational use of biological characteristics of a variety or hybrid, a background of nutrition, heat and moisture - its transpiration factor in the range 190-220 [9].

The removal of nitrogen, phosphorus and potassium per 1 ton of the main and byproduct - respectively 29,11 and $26 \mathrm{~kg}$, so most soils, where sow sorghum, provide only half of the required nutrition elements, hence the rest of the nutrients need to replenish at the expense of fertilizers, the norm is determined on the basis of agrochemical analysis of the soil and the density of plant standing $[9,10]$.

It has been proved that the application of foliar fertilization also positively affects the productivity of sugar sorghum, sugar yield and bioethanol from it. As a result of studies conducted at the State Agrarian and Engineering University in Podilya, it was found that due to the introduction of $\mathrm{N}_{60} \mathrm{P}_{60} \mathrm{~K}_{60}$ in the autumn, and in spring, the introduction of foliar feeding of sorghum into the batching phase with a complex microfertilizer, Yarylo (3 1 / ha), the sugar harvest increased to 8.68 tons / ha, which is more than $0,88 \mathrm{t} /$ ha more than control. At the same time, the output of bioethanol was also increased and for the harvesting of sugar sorghum in the phase of waxy ripeness ranged from 2.26 to $2.58 \mathrm{t} / \mathrm{ha}$ [11].

\section{Conditions and methods of research}


The research was conducted at theState Agrarian and Engineering University in Podilya during 2014-2017.

The soil of the experimental field is black earth mined, slightly humus, on carbonate lignified loams. The content of humus in a layer of soil is $0-30 \mathrm{~cm}$ (by Tyurin $-3.86-4.11 \%$; easily hydrolyzed nitrogen (according to Cornfield) - 111-121 mg / kg, mobile phosphorus and exchangeable potassium (according to Chirikov) - respectively, 90 and $179 \mathrm{mg} / \mathrm{kg}$ of soil.The absorption capacity and the amount of absorbed bases fluctuates accordingly within the limits of 33-36 and 30-33 mg equivalents / $100 \mathrm{~g}$ of soil Hydrolytic acidity is 0,76-0,87 mg-eq / $100 \mathrm{~g}$ of soil, the degree of saturation with the basics - 94,7-99,0\%.

The density of the solid phase is $2.58 \mathrm{~g} / \mathrm{cm}^{3}$, the density of the structure of the soil $1.14-1.25 \mathrm{~g} / \mathrm{cm}^{3}$, total spout - 52-59\%. Maximum soil hygroscopicity $5.2 \%$; the lowest moisture content $-23,4 \%$, the full field $-41,2 \%$.

The climate of the southwestern forest-steppe of Ukraine is warm, with a sufficient amount of moisture. The average annual radiological balance in the region is $43.3 \mathrm{kcal} /$ $\mathrm{cm}^{2}$, and during the growing season of sorghum $-137.73 \mathrm{~kJ} / \mathrm{cm}^{2}$. Physical activity radiation is the most frequent in June and July. During the period from May to September, $3 / 4$ annual amount of heat comes to the surface of the soil.

The annual amount of precipitation varies within $550-700 \mathrm{~mm}, 3 / 4$ of them fall in the warm period of the year. In the years of researches the amount of precipitation and the sum of temperatures of the growing season of sugar sorghum fluctuated in such limits. The hydrothermal coefficient in the region is an average of 1.4.

Field studies on the study of elements of technology for growing sorghum sugar for use in biofuel production were carried out as follows:

Factor A. Power supply.

1. Control - without fertilizers.

2. $\mathrm{N}_{90} \mathrm{P}_{90} \mathrm{~K}_{90}$.

3. $\mathrm{N}_{120} \mathrm{P}_{120} \mathrm{~K}_{120}$.

Factor B. Grain or Sorghum hybrid:

1. Sugar 1.

2. Honey F1.

Factor B. Application of herbicide on stairs of dicotyledonous weeds:

1. Control - no herbicides.

2. 2,4-D amine salt 1,51/ ha.

The area of the unitary sown area is $108 \mathrm{~m}^{2}(5.4 \times 20 \mathrm{~m})$, the record is $72 \mathrm{~m}^{2}(4.5 \times 16$ $\mathrm{m})$, repetition was four times. The experiment was laid out using the split plot method - the background of the feeder - in two blocks, varieties and herbicides - consistently in one tier.

\section{Features of the technology of cultivating sugar sorghum in the experiment}

Sorghum variety sugar "Sugar 1".Originator: Institute of agriculture of the steppe zone of the National Academy of Sciences of Ukraine. Method of creation: cross-breeding of samples of sugar sorghum with further selection of productivity and high content of sugars in juicy plants. Seed production of sort is reliable.

It is recommended for growing on silage, green fodder and for production of liquid sugar. The height of plants is $195-275 \mathrm{~cm}$. The stalk is well leafy, green, juicy with juice 
content up to $17-22 \%$. Productive bushiness of 2,0-2,5 stems per plant. Panicle spreading, upright, well-filled with grain.

Biological signs: mid-life, economic suitability (milk-waxy ripeness of grain) reaches 110-115 days after the ladder. Maturation of grain on the panicle of the main and lateral stems is practically simultaneous.

Economic characteristics: the green mass harvest in favorable years reaches $45 \mathrm{t} / \mathrm{ha}$, in arid - 20-26 $\mathrm{t} / \mathrm{ha}$. The content of panicle with the grain of the milky-wax ripeness in the leaf-massive mass, depending on the conditions of cultivation, is 6.0-11.0 t/ ha.

The grade is poorly responsive to the cooler periods of spring, is slightly damaged by cereal aphids, is well responsive to irrigation and fertilization. Density of standing during harvesting: under irrigation - 250 thousand plants / ha; on rain-fed lands - 140 thousand plants / ha. The cultivation technology is commonly used for sugar sorghum.

Hybrid sugar Sorghum "Honey F1". Initiator: Selection-Genetic Institute - National Center for Seed Education and Standard Studies.

It is recommended for growing on silage and green mass, obtaining sweet juice and products of its processing (syrup, bioethanol). High-yielding, yields 50-60 t / ha of leafmass on on rain-fed lands and up to $100 \mathrm{t} / \mathrm{ha}$ in irrigation. The content of soluble carbohydrates in juice of stems is $17-18 \%$. Medium-growing, vegetative period to milk-wax ripeness of grain 90-100 days; resistant to plunging with long staing on the stump, well suited for mechanized harvesting. Cold resistance during seed germination is high; Not affected by illness and weakly damaged by aphids.

Characterized by economically advantageous seed production. Approbation features: first-generation hybrid, tall $(270-290 \mathrm{~cm})$, leafy stems medium $(12-13$ leaves per stem), thick (20-25 mm), juicy core. Bushiness- 4-5 stems per plant. It has an elliptical shape, brown, weak-wicking. The length of the leg is $15-25 \mathrm{~cm}$. Grains are medium, 3/4 closed, brown. Weight of 1000 seeds of raw is $25-30 \mathrm{~g}$.

Agrotechnical requirements: for obtaining friendly stairs requires a well-balanced field and seeding in moist soil to a depth of $5-6 \mathrm{~cm}$. The best way to sow - broad-row. The optimum density at the time of harvesting during the cultivation of fodder for the south of Ukraine is 75-80 thousand plants / ha, for the forest-steppe and Polissya - 100-120 thousand plants / ha. Seeds for the production of sweet juice should have a density of 15-20\% less.

The technology of cultivating sugar sorghum, with the exception of the investigated elements, was common for the forest-steppe of Ukraine.

The predecessor to the sugar sorghum was winter wheat. The main cultivation of the soil consisted of soil discrepancies at a depth of 6-7 cm and gill cultivation at a depth of 25$27 \mathrm{~cm}$. The purpose of the early spring and preplant soils was to preserve the moisture accumulated during the winter, to destroy the weeds and create favorable conditions for germination of the seeds and getting friendly and full stairs.

In the spring, during physical ripeness of the soil, closed with moisture. Before cultivating the experiment, mineral fertilizers were introduced and cultivated. Sorghum was seeded with a beet seed drill SST-12 with a width of $45 \mathrm{~cm}$ spacing with a seed rate of 140150 thousand seeds per hectare at a depth of $4-6 \mathrm{~cm}$ when the average daily temperature of the soil at a depth of $10 \mathrm{~cm}$ was $13-15^{\circ} \mathrm{C}$ (last decade April - the first decade of May). Before sowing, the seeds of the sorghum were treated with an antidote of Contsep III 960 EC $(0,31 / t)$ to prevent damage to the stairs by a herbicide of 2,4-D amine salt in a 3-5-leaf phase at a rate of 1.5 liters per hectare. Spraying was carried out in a sunny, dry weather at a temperature of 16 to $24^{\circ} \mathrm{C}$. Mechanical measures for controlling the number of weeds provided two inter-row cultivators with a cultivator KRNV-5,6-04: the first - in the phase of 3-4 leaves to a depth of 7-8 cm, the second - in two weeks in the phase of 5-7 leaves. A 
month after sowing, sugar sorghum plants formed sufficient vegetative mass, which allowed them to prevent the appearance of weeds.

The start of harvesting of sugar sorghum on biomass is determined by the content of dry matter in biomass - at least $30 \%$. To produce juice, which is raw material for the production of bioethanol, sugar sorghum began to be collected in the phase of waxy ripeness, when the stem contains about $70-80 \%$; the mass is used for the manufacture of solid fuel after spinning the juice.

\section{Research results}

The species composition of weeds in the sorghum seedlings after the staircase during the years of research has changed as follows: prevailing annual grasses - yellow bristlegrass and barnyard-grass; Among the two-year-old dicotyledons - catchweed bedstrow, black-berry nightshade, white loboda, thalaban, gritski usual, stellaria media, field violet, chamomile odorless and others. The average number of weeds during the years of research on the control without the addition of 2,4-D was 86 units. / $\mathrm{m} 2$, in the variant of introduction of a 2,4-D herbicide at a rate of $1.51 /$ ha in the phase of 3-4 leaves - from 11 and 27 units. / $\mathrm{m} 2$

Biometric indices of sugar sorghum plants depending on the influence of the elements of cultivation technology in the phase of full grain ripeness are given in Table. 1

Table 1. Biometric indicators sorghum sugar plant (average for 2014-2017)

\begin{tabular}{|l|c|c|}
\hline \multicolumn{2}{|l|}{ Sort Sugar 1 } & $\begin{array}{l}\text { Hybrid } \\
\text { Honey F 1 }\end{array}$ \\
\hline Sorghum Plant height, cm & 218 & 226 \\
\hline Control - without chemical treatments & 223 & 231 \\
\hline Herbicide 2,4-D on the background of $\mathrm{N}_{90} \mathrm{P}_{90} \mathrm{~K}_{90}$ & 238 & 245 \\
\hline Herbicide 2,4-D on the background $\mathrm{N}_{120} \mathrm{P}_{120} \mathrm{~K}_{120}$ & & \\
\hline HIP $05=18$ & 16,5 & 17,2 \\
\hline Diameter of stem of sorghum plants, $\mathrm{mm}^{\mid}$ & 18,5 & 19,1 \\
\hline Control - without chemical treatments & 21,3 & 21,7 \\
\hline Herbicide 2,4-D on the background of $\mathrm{N}_{90} \mathrm{P}_{90} \mathrm{~K}_{90}$ & & \\
\hline Herbicide 2,4-D on the background $\mathrm{N}_{120} \mathrm{P}_{120} \mathrm{~K}_{120}$ & & \\
\hline HIP $05=2,3$ & & 2 \\
\hline
\end{tabular}

For the introduction of sorghum herbicide 2,4-D in the steps of $1.51 /$ ha in the phase of 3-4 leaves, there was a good increase in plant height and diameter of the stems.

The greatest influence on the level of green weight of sorghum sugar was fertilizer.

By the rules of their introduction $\mathrm{N}_{90} \mathrm{P}_{90} \mathrm{~K}_{90}$ the average yield increase compared to the control without fertilizers of the Sugar 1 variety was 6.1 tons / ha, and the Honey F1 hybrid was 6.5 tons / ha; for the norm $\mathrm{N}_{120} \mathrm{P}_{120} \mathrm{~K}_{120}$ - respectively, 7.9 and $8.6 \mathrm{t} /$ ha (Table 2). 
Table 2. Yield of green mass of sugar sorghum, $\mathrm{t} /$ ha (average for 2014-2017)

\begin{tabular}{|c|c|c|c|c|c|c|c|c|}
\hline \multirow{2}{*}{$\begin{array}{l}\text { Background } \\
\text { nutrition }\end{array}$} & \multirow{2}{*}{$\begin{array}{l}\text { A grade } \\
\text { or a } \\
\text { hybrid }\end{array}$} & \multirow{2}{*}{$\begin{array}{l}\text { Herbici } \\
\text { de }\end{array}$} & \multicolumn{4}{|c|}{ Year of research } & \multirow{2}{*}{$\begin{array}{l}\text { Averag } \\
\text { e }\end{array}$} & \multirow{2}{*}{$\begin{array}{l} \pm \\
\text { before } \\
\text { control }\end{array}$} \\
\hline & & & 2014 & 2015 & 2016 & 2017 & & \\
\hline \multirow{4}{*}{$\begin{array}{l}\text { Control - } \\
\text { without } \\
\text { fertilizers }\end{array}$} & \multirow{2}{*}{ Sugar 1} & control & 69,7 & 33,7 & 39,4 & 51,6 & 48,6 & - \\
\hline & & $2.4 \mathrm{D}$ & 71,8 & 35,6 & 41,9 & 53,9 & 50,8 & 2,2 \\
\hline & \multirow{2}{*}{ Honey F1 } & control & 71,2 & 35,3 & 41,5 & 53,4 & 50,4 & - \\
\hline & & $2.4 \mathrm{D}$ & 74,3 & 36,9 & 43,4 & 55,8 & 52,6 & 2,3 \\
\hline \multirow{4}{*}{$\mathrm{N}_{90} \mathrm{P}_{90} \mathrm{~K}_{90}$} & \multirow{2}{*}{ Sugar 1} & control & 77,3 & 38,4 & 45,1 & 58,0 & 54,7 & - \\
\hline & & $2.4 \mathrm{D}$ & 79,0 & 40,4 & 47,5 & 61,1 & 57,0 & 2,3 \\
\hline & \multirow{2}{*}{ Honey F1 } & control & 79,0 & 40,1 & 47,1 & 60,6 & 56,7 & - \\
\hline & & $2.4 \mathrm{D}$ & 83,9 & 41,7 & 49,0 & 63,1 & 59,4 & 2,7 \\
\hline \multirow{4}{*}{$\mathrm{N}_{120} \mathrm{P}_{120} \mathrm{~K}_{120}$} & \multirow{2}{*}{ Sugar 1} & control & 79,8 & 39,6 & 46,6 & 59,9 & 56,5 & - \\
\hline & & $2.4 \mathrm{D}$ & 82,0 & 41,7 & 49,0 & 63,0 & 58,9 & 2,4 \\
\hline & \multirow{2}{*}{ Honey F1 } & control & 83,3 & 41,3 & 48,6 & 62,5 & 58,9 & - \\
\hline & & $2.4 \mathrm{D}$ & 86,5 & 42,9 & 50,4 & 62,5 & 60,6 & 1,7 \\
\hline
\end{tabular}

$\mathrm{HIP}_{05}=$ background of nutrition 3,4, a grade or a hybrid and a herbicide 3,9

The increase in yield between varieties and in variants using herbicide 2,4-D was within the experimental error, but there were some positive trends in these variants, namely: the hybrid Honey F1 was consistently above the yield level of Sorghum Sugar 1, herbicide 2.4 -D all years had a positive effect. 


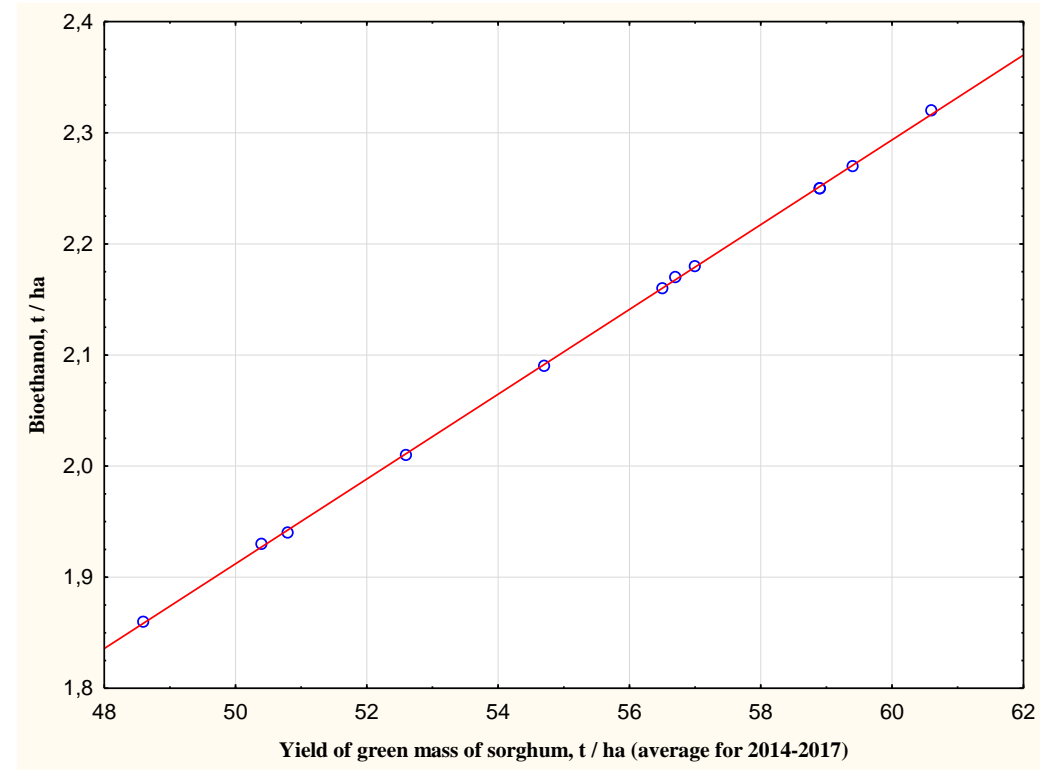

Energy efficiency of the technology of cultivating sugar sorghum Sugar 1 and the Honey F1 hybrid for biofuel production are high: against the background of introducing $\mathrm{N}_{90} \mathrm{P}_{90} \mathrm{~K}_{90}$ and application of the herbicide 2,4-D, the bioethanol yield was respectively 2.18 and $2.27 \mathrm{t} / \mathrm{ha}$, respectively solid fuel - 11, 9 and $12.4 \mathrm{t} / \mathrm{ha}$, bioenergy - respectively 243 and $254 \mathrm{GJ}$; on the background of the introduction of $\mathrm{N}_{120} \mathrm{P}_{120} \mathrm{~K}_{120}$ and the application of 2,4-D herbicide, the bioethanol yield was 2.25 and $2.32 \mathrm{t} /$ ha respectively, solid fuels respectively 12.3 and $12.6 \mathrm{t} / \mathrm{ha}$, bioenergy - respectively 252 and 259 GJ.

Energy value of green mass of sorghum depending on the influence of investigated elements of cultivation technology is given in Table. 3

Table 3. Output of bioethanol, solid biofuels and energy depending on the application of elements of the technology of cultivating sugar sorghum (average for 2014-2017).

\begin{tabular}{|c|c|c|c|c|c|}
\hline $\begin{array}{l}\text { Background } \\
\text { nutrition }\end{array}$ & $\begin{array}{l}\text { A grade or a } \\
\text { hybrid }\end{array}$ & Herbicide & $\begin{array}{l}\text { Bioethanol, t } \\
\text { / ha }\end{array}$ & $\begin{array}{l}\text { Solid } \\
\text { biofuels, t / } \\
\text { ha }\end{array}$ & $\begin{array}{l}\text { Bioenergy, } \\
\text { GJ }\end{array}$ \\
\hline \multirow{4}{*}{$\begin{array}{l}\text { Control - } \\
\text { without } \\
\text { fertilizers }\end{array}$} & \multirow{2}{*}{ Sugar 1} & control & 1,86 & 10,1 & 208 \\
\hline & & $2.4 \mathrm{D}$ & 1,94 & 10,6 & 217 \\
\hline & \multirow{2}{*}{ Honey F1 } & control & 1,93 & 10,5 & 215 \\
\hline & & $2.4 \mathrm{D}$ & 2,01 & 10,9 & 225 \\
\hline \multirow{4}{*}{$\mathrm{N}_{90} \mathrm{P}_{90} \mathrm{~K}_{90}$} & \multirow{2}{*}{ Sugar 1} & control & 2,09 & 11,4 & 234 \\
\hline & & $2.4 \mathrm{D}$ & 2,18 & 11,9 & 243 \\
\hline & \multirow{2}{*}{ Honey F1 } & control & 2,17 & 11,8 & 242 \\
\hline & & $2.4 \mathrm{D}$ & 2,27 & 12,4 & 254 \\
\hline \multirow{4}{*}{$\mathrm{N}_{120} \mathrm{P}_{120} \mathrm{~K}_{120}$} & \multirow{2}{*}{ Sugar 1} & control & 2,16 & 11,7 & 241 \\
\hline & & $2.4 \mathrm{D}$ & 2,25 & 12,3 & 252 \\
\hline & \multirow{2}{*}{ Honey F1 } & control & 2,25 & 12,3 & 252 \\
\hline & & $2.4 \mathrm{D}$ & 2,32 & 12,6 & 259 \\
\hline
\end{tabular}




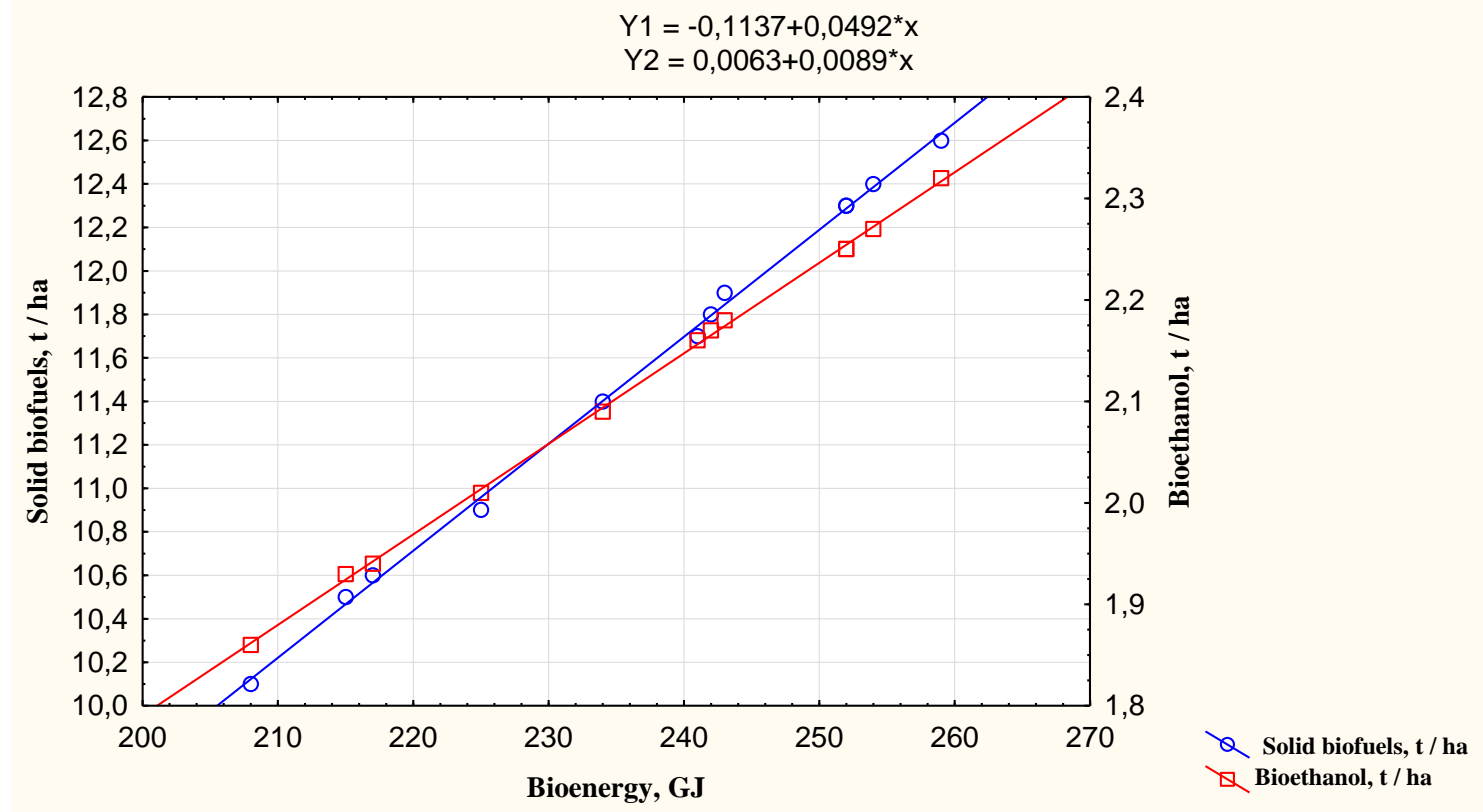

\section{Conclusions}

1. For the introduction of sorghum herbicide 2,4-D in the steps of 1.51 / ha in the phase of 3-4 leaves, there was a good increase in plant height and diameter of the stems.

2. Increase in the yield of green mass of sorghum compared to non-fertilized control for the norm $\mathrm{N}_{90} \mathrm{P}_{90} \mathrm{~K}_{90}$ of the grade Sugar 1 was $6.1 \mathrm{t} / \mathrm{ha}$, and the hybrid Honey F1 - $6.5 \mathrm{t} / \mathrm{ha}$; for the norm $\mathrm{N}_{120} \mathrm{P}_{120} \mathrm{~K}_{120}$ respectively 7.9 and $8.6 \mathrm{t} / \mathrm{ha}$.

3. For the production of biofuels, the energy efficiency of the cultivating technology of the sugar sorghum cultivar Sugar 1 and the Honey F1 hybrid was: against the background of the introduction of $\mathrm{N}_{90} \mathrm{P}_{90} \mathrm{~K}_{90} \mathrm{i}$ and the application of a 2,4-D herbicide, bioethanol yield, respectively, of 2.18 and $2.27 \mathrm{t} / \mathrm{ha}$, respectively, of solid fuels - respectively 11,9 and 12,4 t / ha, bioenergy - respectively 243 and $254 \mathrm{GJ}$; on the background of the introduction of $\mathrm{N}_{120} \mathrm{P}_{120} \mathrm{~K}_{120}$ and the application of 2,4-D herbicide, the bioethanol yield was 2.25 and $2.32 \mathrm{t} /$ ha respectively, solid fuels - respectively 12.3 and $12.6 \mathrm{t} / \mathrm{ha}$, bioenergy - respectively 252 and 259 GJ.

\section{References}

1. Energy Strategy of Ukraine for the period up to 2035 Decree of the Cabinet of Ministers of Ukraine dated August 18, 2017 No. 605

2. Royik, M. V., Kurylo, V. L., Hanzhenko, O. M., Humentyk, M. Y. State and prospects of bioenergy development in Ukraine. Collection of scientific works, Institute of Bioenergy Crops and Sugar Beet. 13, 93-103 (2012) 
3. Geletukha, G. G., Zhelyezna, T. A., Tyshayev, S. V. and others. The concept of bioenergy development in Ukraine. Kiev, K.: Institute of Thermal Physics, The Academy of Sciences of Ukraine (2001)

4. Kirichenko, L.V., Rozhenko V.P., Filonenko, L.I. and others. New application of sugar sorghum. Agrobusiness today, 23 (222), 25-26 (2011)

5. Grey K.A., Zhao L., Emptage M. Bioethanol. Curr. Opin. Chem. Biol., 10, 1-6 (2006)

6. Moroz O. M., Smirny V. O., Shopish G. M. Sorgo Sugar as an energy culture. Agronomy, 1, 204-205 (2013)

7. Mulyarchuk,O. I., Mishchenko,Y. G., Masik,I. M., Davidenko,G. A. Biofuel from sugar sorghum. Bulletin SNAU Series: Agriculture and Biology, 3(27), 99-103 (2014)

8. Kurilov V. L., Ganzhenko O. M., Gomentyk M. Y. Productivity of sugar sorghum for biofuel production. Collection of scientific works of IBCsSB, 13, 115-125 (2012)

9. Ganzhenko, O. M. Sugar Sorghum: The Ukrainian Farmer, 10, $42-44$ (2012)

10. Cherenkov A.V., Shevchenko M.S., Dzyubetskii B.V. and others. Cereals: technology, use, hybrids and varieties. Recommendations Dnipropetrovsk, 25 p. (2011)

11. Mulyarchuk O.I, Koberniuk, O.T, Influence of mineral nutrition on the yield of bioethanol from sugar sorghum. Podilsky Gazette: agriculture, engineering, economics, Kamyanets-Podilsky, 26 (1), 94-101 (2017). 